www.nature.com/pj

\title{
Transformation from preformed racemic helical poly(phenylacetylene)s to the enantioenriched helical polymers by chiral solvation, followed by removal of the chiral solvents
}

\author{
Takashi Kaneko ${ }^{1,2,3,4}$, Xiaoyun Liang ${ }^{1}$, Atsuko Kawami ${ }^{2}$, Masayuki Sato², Takeshi Namikoshi ${ }^{3,5}$, \\ Masahiro Teraguchi ${ }^{1,2,3,4}$ and Toshiki Aoki ${ }^{1,2,3,4,5}$
}

\begin{abstract}
Homochiral or enantioenriched helical polymers are essential for investigating the relationship between chirality of helical structures and their performance in the design of various optically active functional polymers. We have succeeded in obtaining the helical poly(phenylacetylene)s poly(1)-poly(6) possessing no chiral moieties, except for helicity; the enantioenriched helical sense of these polymers was induced by transformation in chiral solvents, followed by removal of the chiral solvents, even if the interaction between the chiral molecule and the polymer was weak such as solvent-solute interaction. In particular, the newly synthesized poly(6) retained the induced helical sense even in an achiral solvent.
\end{abstract}

Polymer Journal (2012) 44, 327-333; doi:10.1038/pj.2011.144; published online 18 January 2012

Keywords: chiral field; $\pi$-conjugated polymers; optically active helical polymers; poly(phenylacetylene)

\section{INTRODUCTION}

Synthesis and processing of optically active helical polymers have recently attracted much attention in the field of intelligent polymer architecture. ${ }^{1-4}$ In particular, homochiral or enantioenriched helical polymers, the chirality of which is caused only by their helical conformation, will be useful for the design of optically active functional polymers and for the study of the relationship between chirality of helical structures and their performance. Effective approaches for obtaining these helical polymers include helix-sense-selective polymerization (HSSP) of achiral monomers in the presence of chiral catalysts $^{5-11}$ or in a chiral field ${ }^{12-14}$ and the removal of a chiral side group from an optically active helical polymer bearing the chiral moiety. We have already succeeded in using the above methods to obtain poly(phenylacetylene)s with an induced kinetically stabilized helical bias. ${ }^{15-19}$ Another approach is the use of external chiral stimuliinduced or chiral field-induced transformation from a racemic helical or achiral polymer to an enantioenriched helical polymer. In this approach, the chiral helical bias has often been induced by strong interactions such as acid-base interaction $\mathrm{s}^{20-25}$ and host-guest interactions ${ }^{26-31}$ between a chiral molecule and a polymer. In these cases, the polymer requires a functional group to interact with the chiral molecule, which may restrict the molecular design of optically active functional polymers. Moreover, the right- and left-handed helical structures are more similar to diastereomers than enantiomers because the external non-racemic chiral molecules strongly interact with specific sites on the polymer. By contrast, Green et al. demonstrated the induction of preferential helical sense by weak interaction between a chiral molecule and a polymer, that is, by solvation of the polymer in an optically active solvent, such as by dissolving poly(hexylisocyanate) in optically active chloroalkane solvents. ${ }^{32,33}$ The helical polymer possessing no chiral moieties except for helicity has two conformational enantiomers the states of which are thermodynamically equivalent to one another, and the optically active solvents induced a very small energetic preference per monomer residue for one conformational enantiomer. However, the energy difference was greatly amplified in the polymer by the length of the helical sequences when a high energetic cost of helical reversals in the polymer chain was required. Consequently, Green et al. predicted the applicability of this method to other examples of a large number of dynamically racemic helical polymers. However, there are only a few examples of helical polymers the optical activity of which observed in solution is due to the chiral helical bias induced by weak interaction, ${ }^{34}$ such as chiral solvation, although there have been reports on polymer aggregates exhibiting preferential helicity in optically active media. ${ }^{35-38}$ Moreover, inducing

${ }^{1}$ Department of Chemistry and Chemical Engineering, Niigata University, Niigata, Japan; ${ }^{2}$ Graduate School of Science and Technology, Niigata University, Niigata, Japan; ${ }^{3}$ Center for Transdisciplinary Research, Niigata University, Niigata, Japan; ${ }^{4}$ Center for Education and Research on Environmental Technology, Materials Engineering, and Nanochemistry, Institute of Science and Technology, Niigata University, Niigata, Japan and ${ }^{5}$ Venture Business Laboratory, Niigata University, Niigata, Japan

Correspondence: Dr T Kaneko, Department of Chemistry and Chemical Engineering, Niigata University, Ikarashi 2-8050, Niigata 950-2181, Japan.

E-mail: kanetaka@gs.niigata-u.ac.jp

Received 7 September 2011; revised 17 November 2011; accepted 23 November 2011; published online 18 January 2012 
a preferential helical sense in an optically active solvent requires removing and recovering the chiral solvent for the economy of chiral molecules and for formation of the helical polymer without any other chiral source. In this study, we found that a number of poly(phenylacetylene)s (poly(1)-poly(6)) showed induction of a preferential helical sense in optically active solvents and resulted in enantioenriched helical polymers after the removal of chiral solvents. In particular, the newly synthesized poly $(6)$ retained the induced helical sense, even in an achiral solvent.

\section{EXPERIMENTAL PROCEDURE}

\section{Materials}

[4-(Trimethylsilyl)phenyl]acetylene (2) and poly $(2) \quad\left(\mathrm{M}_{\mathrm{n}}=2.7 \times 10^{4}, \mathrm{M}_{\mathrm{w}} /\right.$ $\mathrm{M}_{\mathrm{n}}=4.6$ ) were synthesized as described previously. ${ }^{39}$ 2-Bromo-6-(3-methyl-3tetrahydropyranyloxy-1-butynyl)anthracene was synthesized from 2,6-dibromoanthracene according to a method in the literature. ${ }^{40,41} 1$-Bromo- $4-[($ trimethylsilyl)ethynyl]benzene ${ }^{42}$ and benzyl 2,4,6-trihydroxybenzoate. ${ }^{43}$ were synthesized according to respective methods in the literature. Tetrakis(triphenylphosphine)palladium $(0)\left(\mathrm{Pd}\left(\mathrm{PPh}_{3}\right)_{4}\right)$ (Aldrich, St Louis, MO, USA), bis(triphenylphosphine)palladium(II) chloride $\left(\mathrm{Pd}\left(\mathrm{PPh}_{3}\right)_{2} \mathrm{Cl}_{2}\right)$ (Aldrich), nbutyllithium (Kanto Chemical, Tokyo, Japan, $1.6 \mathrm{M}$ in hexane) and (bicyclo[2.2.1]hepta-2,5-diene)chlororhodium(I) dimer catalyst $\left([\mathrm{Rh}(\mathrm{nbd}) \mathrm{Cl}]_{2}\right)$ (Aldrich) were used without further purification. Other conventional reagents were used as received or purified by conventional methods.

\section{Synthesis of monomers}

[(3,5-Di-tert-butyl-4-hydroxyphenyl)phenyl]acetylene (3). A two-necked flask was charged with zinc chloride $(1.09 \mathrm{~g}, 8.0 \mathrm{mmol})$ that was heated and dried under a rapid stream of nitrogen. After the flask was cooled at room temperature, [3,5-di-tert-butyl-4-(trimethylsilyl)phenyl]phenyllithium prepared from $1.56 \mathrm{M} n$-butyllithium $(10 \mathrm{ml})$ and [3,5-di-tert-butyl-4-(trimethylsilyl)phenyl]phenylbromide $(2.86 \mathrm{~g}, 8 \mathrm{mmol})$ in dry tetrahydrofuran (THF) $(17 \mathrm{ml})$ at $-70{ }^{\circ} \mathrm{C}$ was added to the flask under a nitrogen atmosphere. The mixture was stirred for $2 \mathrm{~h}$ and added to a dry THF $(9 \mathrm{ml})$ solution of 1bromo-4-[(trimethylsilyl)ethynyl]benzene $(1.0 \mathrm{~g}, 4 \mathrm{mmol})$ with $\mathrm{Pd}\left(\mathrm{PPh}_{3}\right)_{4}$ ( $92 \mathrm{mg}, 0.080 \mathrm{mmol}$ ). The mixture was stirred for $24 \mathrm{~h}$ at room temperature, then treated with saturated aqueous $\mathrm{NaCl}(250 \mathrm{ml})$, extracted with chloroform and washed with water. The chloroform layer was dried over anhydrous sodium sulfate. After evaporation, the crude product was dissolved in methanol $(50 \mathrm{ml})$, and potassium carbonate $(1.1 \mathrm{~g}, 80 \mathrm{mmol})$ was added to this solution. After stirring for $12 \mathrm{~h}$ at room temperature, the mixture was extracted with chloroform and washed with water. The chloroform layer was dried over anhydrous sodium sulfate and evaporated. The crude product was purified by silica-gel column separation to yield $3(0.37 \mathrm{~g}, 1.2 \mathrm{mmol})$. Yield $31 \%$, mp $117-$ $118^{\circ} \mathrm{C}$. Infrared (IR) $\left(\mathrm{KBr}, \mathrm{cm}^{-1}\right) 3632\left(v_{\mathrm{O}-\mathrm{H}}\right), 2958\left(v_{\mathrm{C}-\mathrm{H}}\right.$, tert-butyl). ${ }^{1} \mathrm{H}$ nuclear magnetic resonance (NMR) $\left(\mathrm{CDCl}_{3}, 270 \mathrm{MHz}\right.$; p.p.m.) $\delta 1.49(\mathrm{~s}, 18 \mathrm{H}$, tert-butyl), $3.11(\mathrm{~s}, 1 \mathrm{H}, \mathrm{C} \equiv \mathrm{C}-\mathrm{H}), 5.31(\mathrm{~s}, 1 \mathrm{H}, \mathrm{OH}), 7.39(\mathrm{~s}, 2 \mathrm{H}, \mathrm{PhH}), 7.51(\mathrm{~d}$, $2 \mathrm{H}, J=8.7 \mathrm{~Hz}, \mathrm{ArH}), 7.52$ (d, $2 \mathrm{H}, J=8.7 \mathrm{~Hz}, \mathrm{ArH}) .{ }^{13} \mathrm{C} \mathrm{NMR}\left(\mathrm{CDCl}_{3}\right.$; p.p.m.): $\delta$ $30.36,34.53,78.1,83.78,119.83,123.81,126.62,131.38,132.31,132.52,136.20$, 142.43. Anal. calcd. for $\mathrm{C}_{22} \mathrm{H}_{26} \mathrm{O}$ : C, 86.23; H, 8.55. Found: C, 86.20; H, 8.63.

2-(3,5-Di-tert-butyl-4-hydroxyphenyl)-6-ethynylanthracene (4). 2-Bromo-6-(3methyl-3-tetrahydropyranyloxy-1-butynyl)anthracene $(1.0 \mathrm{~g}, 2.4 \mathrm{mmol})$ allowed to react with [3,5-di-tert-butyl-4-(trimethylsilyl)phenyl]phenyllzinc chloride in the same manner as described above, followed by the removal of the protecting group in the usual manner. The crude product was purified by silica-gel column separation to yield $4(0.17 \mathrm{~g}, 0.42 \mathrm{mmol})$. Yield $17 \%$. IR $\left(\mathrm{KBr}, \mathrm{cm}^{-1}\right) 3632$ $\left(v_{\mathrm{O}-\mathrm{H}}\right), 2958\left(v_{\mathrm{C}-\mathrm{H}}\right.$, tert-butyl). ${ }^{1} \mathrm{H}$ NMR $\left(\mathrm{CDCl}_{3}, 270 \mathrm{MHz}\right.$; p.p.m.) $\delta 1.54$ (s, $18 \mathrm{H}$, tert-butyl), 3.20 (s, $1 \mathrm{H}, \mathrm{C} \equiv \mathrm{C}-\mathrm{H}), 5.34(\mathrm{~s}, 1 \mathrm{H}, \mathrm{OH}), 7.46$ (dd, $1 \mathrm{H}, J=8.8$, $1.6 \mathrm{~Hz}, \mathrm{ArH}), 7.58(\mathrm{~s}, 2 \mathrm{H}, \mathrm{PhH}), 7.76(\mathrm{dd}, 1 \mathrm{H}, J=8.8,1.6 \mathrm{~Hz}, \mathrm{ArH}), 7.94(\mathrm{~d}, 1 \mathrm{H}$, $J=8.8 \mathrm{~Hz}, \mathrm{ArH}), 8.05(\mathrm{~d}, 1 \mathrm{H}, J=8.8 \mathrm{~Hz}, \mathrm{ArH}), 8.10(\mathrm{~d}, 1 \mathrm{H}, J=1.6 \mathrm{~Hz}, \operatorname{ArH}), 8.20$ $(\mathrm{d}, 1 \mathrm{H}, J=1.6 \mathrm{~Hz}, \mathrm{ArH}), 8.38(\mathrm{~s}, 1 \mathrm{H}, \mathrm{ArH}), 8.43(\mathrm{~s}, 1 \mathrm{H}, \mathrm{ArH}) .{ }^{13} \mathrm{C} \mathrm{NMR}$ $\left(\mathrm{CDCl}_{3}\right.$; p.p.m.): $\delta 30.36,34.55,77.80,84.33,118.49,124.25,124.66,126.18$, $126.22,126.43,127.59,128.25,128.64,130.64,131.01131 .13,132.02,132.67$, 132.97, 136.30, 139.41, 153.85. Anal. calcd. for $\mathrm{C}_{30} \mathrm{H}_{30} \mathrm{O}: \mathrm{C}, 88.63 ; \mathrm{H}, 7.44$. Found: C, 88.26; H, 7.38.
4-(4-Ethynylphenyl)-4-hydroxyl-2,2,6,6-tetramethylpiperidine 1-oxyl (5). A twonecked flask was charged with magnesium $(1.5 \mathrm{~g}, 60 \mathrm{mmol})$ that was heated and dried under a rapid stream of nitrogen. After the flask was cooled at room temperature, 1-bromo-4-[(trimethylsilyl)ethynyl]benzene ( $15 \mathrm{~g}, 60 \mathrm{mmol})$ in THF $(20 \mathrm{ml})$ was added under a nitrogen atmosphere. The mixture was stirred and refluxed for $1 \mathrm{~h}$ to yield the Grignard reagent. The reagent was cooled at room temperature, treated with 2,2,6,6-tetramethyl-4-piperidone $(4.8 \mathrm{~g}, 31 \mathrm{mmol})$ in THF $(6 \mathrm{ml})$ and then stirred at $30-40{ }^{\circ} \mathrm{C}$ for $12 \mathrm{~h}$. After removal of the solvent, $15 \% \mathrm{HCl}(80 \mathrm{ml})$ was added to the reaction mixture and filtered off. The filtrate was treated with saturated aqueous $\mathrm{NaOH}(20 \mathrm{ml})$, and then extracted with ether and washed with water. The ether layer was dried over anhydrous sodium sulfate and evaporated. The excess reactants of the crude product were removed by silicagel column separation with ethyl acetate as an eluent, and the residue was eluted with methanol and evaporated to produce $4-\{4-[($ trimethylsilyl $)$ ethynyl $]$ phenyl $\}$ 4-hydroxyl-2,2,6,6-tetramethylpiperidine $(5.7 \mathrm{~g}, 17 \mathrm{mmol})$. Yield 56\%, mp $108-$ $109^{\circ} \mathrm{C}$. IR $\left(\mathrm{KBr}, \mathrm{cm}^{-1}\right) 3400\left(v_{\mathrm{O}-\mathrm{H}}, v_{\mathrm{C}-\mathrm{H}}\right), 2950\left(v_{\mathrm{C}-\mathrm{H}}\right) .{ }^{1} \mathrm{H}$ NMR $\left(\mathrm{CDCl}_{3}\right.$, $270 \mathrm{MHz}$; p.p.m.) $\delta 0.22\left(\mathrm{~s}, 9 \mathrm{H}, \mathrm{Si}\left(\mathrm{CH}_{3}\right)_{3}\right), 1.20\left(\mathrm{~s}, 6 \mathrm{H}, \mathrm{CH}_{3}\right), 1.40\left(\mathrm{~s}, 6 \mathrm{H}, \mathrm{CH}_{3}\right)$, $1.49(\mathrm{~s}, 1 \mathrm{H}, \mathrm{OH}), 1.67\left(\mathrm{~d}, 2 \mathrm{H}, J=13.6 \mathrm{~Hz}, \mathrm{CH}_{2}\right), 1.80\left(\mathrm{~d}, 2 \mathrm{H}, J=13.6 \mathrm{~Hz}, \mathrm{CH}_{2}\right)$, $2.58(\mathrm{~s}, 1 \mathrm{H}, \mathrm{NH}), 7.41(\mathrm{~s}, 4 \mathrm{H}, \mathrm{PhH})$. The product $(4.9 \mathrm{~g}, 15 \mathrm{mmol})$ was dissolved in methanol $(50 \mathrm{ml})$, and $2.5 \mathrm{M} \mathrm{KOH}$ methanol solution $(10 \mathrm{ml})$ was added to this solution under a nitrogen atmosphere. After stirring for $12 \mathrm{~h}$ at room temperature and evaporation, the mixture was extracted with ether and washed with water. The ether layer was dried over anhydrous sodium sulfate and evaporated. The excess reactants of the crude product were removed by silica-gel column separation with ethyl acetate as an eluent, and the residue was eluted with methanol and evaporated to yield 4-(4-ethynylphenyl)-4-hydroxyl-2,2,6,6-tetramethylpiperidine $(3.4 \mathrm{~g}, 13 \mathrm{mmol})$. Yield $88 \%$, mp $142-143^{\circ} \mathrm{C}$. IR $\left(\mathrm{KBr}, \mathrm{cm}^{-1}\right)$ $3343\left(v_{\mathrm{O}-\mathrm{H}}, v_{\mathrm{N}-\mathrm{H}}\right), 3285\left(v_{\equiv \mathrm{C}-\mathrm{H}}\right), 2950\left(v_{\mathrm{C}-\mathrm{H}}\right) .{ }^{1} \mathrm{H}$ NMR $\left(\mathrm{CDCl}_{3}, 270 \mathrm{MHz}\right.$; p.p.m.) $\delta 1.24\left(\mathrm{~s}, 6 \mathrm{H}, \mathrm{CH}_{3}\right), 1.42\left(\mathrm{~s}, 6 \mathrm{H}, \mathrm{CH}_{3}\right), 1.35(\mathrm{~s}, 1 \mathrm{H}, \mathrm{OH}), 1.69(\mathrm{~d}, 2 \mathrm{H}$, $\left.J=13.5 \mathrm{~Hz}, \mathrm{CH}_{2}\right), 1.83\left(\mathrm{~d}, 2 \mathrm{H}, J=13.5 \mathrm{~Hz}, \mathrm{CH}_{2}\right), 2.68(\mathrm{~s}, 1 \mathrm{H}, \mathrm{NH}), 3.05(\mathrm{~s}, 1 \mathrm{H}$, $\mathrm{C} \equiv \mathrm{C}-\mathrm{H}), 7.46(\mathrm{~s}, 4 \mathrm{H}, \mathrm{PhH})$. Oxidation of the product was performed using a modification of the literature method. ${ }^{44}$ Overall, $30 \%$ hydrogen peroxide $(3.0 \mathrm{ml})$ was added to a solution of the product $(2.6 \mathrm{~g}, 10 \mathrm{mmol})$ and sodium tungstate $(0.17 \mathrm{~g}, 0.50 \mathrm{mmol})$ in water $(5 \mathrm{ml})$ and methanol $(15 \mathrm{ml})$ with stirring at room temperature. After stirring for $14 \mathrm{~h}$ at room temperature, the mixture was treated with saturated aqueous potassium carbonate, extracted with ether and washed with water. The ether layer was dried over anhydrous sodium sulfate, filtered and evaporated. The crude product was purified by silica-gel column separation with ethyl acetate/chloroform $(1 / 4 \mathrm{v} / \mathrm{v})$ as an eluent to yield $\mathbf{5}(2.4 \mathrm{~g}, 8.9 \mathrm{mmol})$. Yield $89 \%$, mp $142-143^{\circ} \mathrm{C}$. Thin layer chromatography (TLC) (ethyl acetate/ chloroform $=1 / 4 \mathrm{v} / \mathrm{v}): \mathrm{Rf}=0.5$. IR $\left(\mathrm{KBr}, \mathrm{cm}^{-1}\right) 3343\left(v_{\mathrm{O}-\mathrm{H}}, v_{\mathrm{N}-\mathrm{H}}\right), 3285$ $\left(v_{\equiv \mathrm{C}-\mathrm{H}}\right), 2950\left(v_{\mathrm{C}-\mathrm{H}}\right), 2100\left(v_{\mathrm{C} \equiv \mathrm{C}}\right)$. Anal. calcd. for $\mathrm{C}_{17} \mathrm{H}_{22} \mathrm{NO}_{2}: \mathrm{C}, 74.97 ; \mathrm{H}$, 8.14; N, 5.14. Found: C, 74.78; H, 8.20; N, 5.09 .

Benzyl 2,6-dihydroxy-4-ethynylbenzoate (6). Triflation ${ }^{45}$ of benzyl 2,4,6-trihydroxybenzoate and protection, ${ }^{46}$ of hydroxyl groups were performed using modification of the respective literature methods. 4-Nitrophenyltriflate $(6.2 \mathrm{~g}$, $23 \mathrm{mmol})$ and potassium carbonate $(8.3 \mathrm{~g}, 60 \mathrm{mmol})$ were added to a solution of benzyl 2,4,6-trihydroxybenzoate $(7.8 \mathrm{~g}, 30 \mathrm{mmol})$ in $\mathrm{N}, \mathrm{N}$-dimethylformamide (DMF) $(300 \mathrm{ml})$ with stirring at room temperature. After stirring for $5 \mathrm{~h}$ at room temperature, the reaction solution was diluted with water $(300 \mathrm{ml})$ and extracted with ethyl acetate. The organic layer was dried over anhydrous sodium sulfate, filtered and evaporated. The residue was filtered through silica-gel column with ethyl acetate/hexane $(1 / 4 \mathrm{v} / \mathrm{v})$ as an eluent. The crude product $(5.0 \mathrm{~g}, 12.7 \mathrm{mmol}$ ) of $\mathrm{Rf}=0.5$ (TLC: ethyl acetate/hexane $=1 / 4 \mathrm{v} / \mathrm{v}$ ), chloromethylmethyl ether $(4.0 \mathrm{ml}, 52 \mathrm{mmol})$ and dichloromethane $(60 \mathrm{ml})$ were stirred at $0{ }^{\circ} \mathrm{C}$ under a nitrogen atmosphere and $\mathrm{N}, \mathrm{N}$-diisopropylethylamine $(18 \mathrm{ml}, 0.10 \mathrm{~mol})$ was added dropwise. After stirring for $4 \mathrm{~h}$ at room temperature, cold saturated aqueous sodium bicarbonate $(71 \mathrm{ml})$ was added to the solution at $0{ }^{\circ} \mathrm{C}$ and the mixture was stirred for $30 \mathrm{~min}$, then treated with water $(355 \mathrm{ml})$, extracted with dichloromethane and washed with saturated aqueous $\mathrm{NaCl}$. The organic layer was dried over anhydrous sodium sulfate, filtered and evaporated. The residue was dissolved in DMF $(24 \mathrm{ml})$, and then chloromethylmethyl ether $(1.8 \mathrm{ml}, 24 \mathrm{mmol})$ was added to the solution at $0^{\circ} \mathrm{C}$. The solution was added to a two-necked flask charged with $60 \%$ sodium hydride $(0.56 \mathrm{~g}, 14 \mathrm{mmol})$ at $0^{\circ} \mathrm{C}$ and then stirred for $30 \mathrm{~min}$ at room temperature. The mixture was treated with water, extracted with ethyl acetate 
and washed with water. The organic layer was dried over anhydrous sodium sulfate, filtered and evaporated. The residue was purified by silica-gel column separation with ethyl acetate/hexane $(1 / 4 \mathrm{v} / \mathrm{v})$ as an eluent to yield benzyl 2,6bis(methoxymethoxy)-4-(trifluoromethanesulfonyloxy)benzoate $\quad(3.5 \mathrm{~g}, \quad 7.3 \mathrm{~m}$ mol). Yield 24\%. TLC (ethyl acetate/hexane $=1 / 4 \mathrm{v} / \mathrm{v}$ ): $\mathrm{Rf}=0.25$. ${ }^{1} \mathrm{H}$ NMR $\left(\mathrm{CDCl}_{3}, 270 \mathrm{MHz}\right.$; p.p.m.) $\delta 3.40\left(\mathrm{~s}, 6 \mathrm{H}, \mathrm{CH}_{3}\right), 5.13\left(\mathrm{~s}, 4 \mathrm{H}, \mathrm{OCH}_{2} \mathrm{O}\right), 5.39$ (s, $\left.2 \mathrm{H}, \mathrm{OCH}_{2} \mathrm{Ph}\right), 6.77$ (s, $\left.2 \mathrm{H}, \mathrm{PhH}\right), 7.34-7.45(\mathrm{~m}, 5 \mathrm{H}, \mathrm{PhH})$. The product $(2.4 \mathrm{~g}$, $5.0 \mathrm{mmol}$ ) and bis(triphenylphosphine)palladium (II) chloride $(0.53 \mathrm{mg}$, $0.75 \mathrm{mmol})$ were dissolved in triethylamine $(15 \mathrm{ml})$ and DMF $(85 \mathrm{ml})$, and trimethylsilylacetylene $(5.5 \mathrm{ml}, 40 \mathrm{mmol})$ was added to this solution under a nitrogen atmosphere. The solution was stirred at $90{ }^{\circ} \mathrm{C}$ for $7 \mathrm{~h}$. The solution was cooled, treated with water, extracted with ether, washed with water and dried over anhydrous sodium sulfate. The solvent was evaporated, and the residue was purified by silica-gel column separation with ethyl acetate/hexane $(1 / 10 \mathrm{v} / \mathrm{v})$ as an eluent to yield benzyl 2,6-bis(methoxymethoxy)-4-[(trimethylsilyl)ethynyl]benzoate $(1.8 \mathrm{~g}, 4.2 \mathrm{mmol}$ ). Yield $84 \%$. TLC (ethyl acetate/hexane $=1 / 10 \mathrm{v} / \mathrm{v}$ ): $\mathrm{Rf}=0.10 .{ }^{1} \mathrm{H} \mathrm{NMR}\left(\mathrm{CDCl}_{3}, 270 \mathrm{MHz}\right.$; p.p.m.) $\delta 0.24$ (s, 9H, $\left.\mathrm{Si}\left(\mathrm{CH}_{3}\right)_{3}\right), 3.40$ (s, $\left.6 \mathrm{H}, \mathrm{CH}_{3}\right), 5.12$ (s, $\left.4 \mathrm{H}, \mathrm{OCH}_{2} \mathrm{O}\right), 5.39$ (s, 2H, OCH$\left.{ }_{2} \mathrm{Ph}\right), 6.90$ (s, 2H, PhH), 7.32 $7.47(\mathrm{~m}, 5 \mathrm{H}, \mathrm{PhH})$. The product $(1.3 \mathrm{~g}, 3.0 \mathrm{mmol})$ and potassium carbonate $(0.041 \mathrm{~g}, 0.30 \mathrm{mmol})$ were dissolved in methanol $(100 \mathrm{ml})$ under a nitrogen atmosphere. After stirring for $5 \mathrm{~h}$ at room temperature and evaporation, the mixture was extracted with dichloromethane and washed with water. The dichloromethane layer was dried over anhydrous sodium sulfate, filtered and evaporated. Benzyl 2,6-bis(methoxymethoxy)-4-[(trimethylsilyl)ethynyl]benzoate $(1.1 \mathrm{~g}, 3.0 \mathrm{mmol})$ was then obtained without further purification. Yield $100 \%$. IR $\left(\mathrm{KBr}, \mathrm{cm}^{-1}\right) 3276\left(v_{\equiv \mathrm{C}-\mathrm{H}}\right), 2962,2919\left(v_{\mathrm{C}-\mathrm{H}}\right), 1732\left(v_{\mathrm{C}=\mathrm{O}}\right) .{ }^{1} \mathrm{H}$ NMR $\left(\mathrm{CDCl}_{3}, 270 \mathrm{MHz}\right.$; p.p.m.) $\delta 3.09(\mathrm{~s}, 1 \mathrm{H}, \mathrm{C} \equiv \mathrm{C}-\mathrm{H}), 3.39\left(\mathrm{~s}, 6 \mathrm{H}, \mathrm{CH}_{3}\right), 5.11(\mathrm{~s}, 4 \mathrm{H}$, $\mathrm{OCH}_{2} \mathrm{O}$ ), 5.39 (s, 2H, OCH$\left.{ }_{2} \mathrm{Ph}\right), 6.95$ (s, 2H, PhH), 7.33-7.45 (m, 5H, PhH). The product $(0.53 \mathrm{~g}, 1.5 \mathrm{mmol})$ was dissolved in THF $(1 \mathrm{ml})$, and $4 \mathrm{~N} \mathrm{HCl}$ $(4.0 \mathrm{ml})$ was added to this solution under a nitrogen atmosphere. The mixture was stirred at $60^{\circ} \mathrm{C}$ for $6 \mathrm{~h}$. The mixture was then cooled, extracted with ether, washed with saturated aqueous $\mathrm{NaCl}$ and dried over anhydrous sodium sulfate. The solvent was evaporated, and the residue was purified by silica-gel column separation with ethyl acetate/hexane $(1 / 4 \mathrm{v} / \mathrm{v})$ as an eluent to yield $6(0.30 \mathrm{~g}$, $1.1 \mathrm{mmol}$ ). Yield $75 \%, \mathrm{mp} 113-114^{\circ} \mathrm{C}$ TLC (ethyl acetate/hexane $=1 / 4 \mathrm{v} / \mathrm{v}$ ): $\mathrm{Rf}=0.43$. IR $\left(\mathrm{KBr}, \mathrm{cm}^{-1}\right) 3391\left(v_{\mathrm{O}-\mathrm{H}}\right), 3299\left(v_{\equiv \mathrm{C}-\mathrm{H}}\right), 2977\left(v_{\mathrm{C}-\mathrm{H}}\right), 1689$ $\left(v_{\mathrm{C}=\mathrm{O}}\right) .{ }^{1} \mathrm{H}$ NMR $\left(\mathrm{CDCl}_{3}, 270 \mathrm{MHz}\right.$; p.p.m.) $\delta 3.19$ (s, 1H, C $\left.\equiv \mathrm{C}-\mathrm{H}\right), 5.50(\mathrm{~s}$, $2 \mathrm{H}, \mathrm{OCH}_{2} \mathrm{Ph}$ ), 6.59 (s, 2H, PhH), 7.43 (br, 5H, PhH), 9.7 (br, $\left.2 \mathrm{H}, \mathrm{PhOH}\right) .{ }^{13} \mathrm{C}$ NMR $\left(\mathrm{CDCl}_{3}\right.$; p.p.m.): $\delta 68.52,80.37,82.25,100.49,111.84,128.85,129.10$, 129.42, 130.07, 133.56, 160.61, 169.01. Anal. calcd. for $\mathrm{C}_{16} \mathrm{H}_{12} \mathrm{O}_{4}$ : C, 71.64; $\mathrm{H}$, 4.51. Found: C, $71.57 ; \mathrm{H}, 4.31$.

\section{Polymerization}

An appropriate amount of monomer (typically, 0.5-1.0 g) was placed in a Schlenk tube equipped with a three-way stopcock, a rubber septum and a Teflon-coated magnetic stirring bar. The tube was placed under vacuum, followed by a nitrogen backflush. A solvent was transferred to the tube, and the monomer was dissolved in the solvent with stirring. The necessary amount of rhodium complex and appropriate amines dissolved in the solvent were added to the stirred monomer solution. The reaction solution was poured into methanol or hexane to yield a polymer precipitate. The precipitate was washed with the precipitant and then dried in vacuo to yield a polymer. The detailed polymerization conditions and results are tabulated in Table 1.

\section{Measurements}

IR spectra were obtained using a Shimadzu FTIR4200 (Shimadzu, Kyoto, Japan) or a Jasco FT/IR-4200 spectrometer (Jasco, Tokyo, Japan). NMR $\left({ }^{1} \mathrm{H}\right.$, ${ }^{13} \mathrm{C}$ ) spectra were measured using a Varian Unity 500SW (Varian, Palo Alto, CA, USA; $500 \mathrm{MHz}$ ) or a Jeol JNM-GSX-270 (Jeol, Tokyo, Japan; 270 MHz) spectrometer. Average molecular weights $\left(M_{n}\right.$ and $\left.M_{w}\right)$ were evaluated by gel permeation chromatography (GPC) calibrated by polystyrene standard at $25^{\circ} \mathrm{C}$ on THF eluent using Jasco liquid chromatograph instruments with PU-2080, DG-2080-53, CO-2060, UV2070, CD-2095 and polystyrene gel columns (Shodex KF-807L; Showa denko, Tokyo, Japan).

Both circular dichroism (CD) and ultraviolet-vis absorption spectra were recorded using a Jasco J-720WI spectropolarimeter with a Peltier controller for temperatures from 50 to $-15^{\circ} \mathrm{C}$ (a quartz cell of $0.1 \mathrm{~cm}$ path length; sample concentration $=0.1-1 \mathrm{~mm}$ based on the monomer unit) and were analyzed using the associated J-700 software (Jasco).

\section{Molecular mechanics calculations}

Molecular mechanics calculations using the Merck Molecular Force Field 94 (MMFF94) were performed on a PC equipped with an Intel Pentium D processor (Intel, Santa Clara, CA, USA, 3.0 GHz) using Spartan '04 for Windows (Wavefunction, Irvine, CA, USA). The optimized helical conformations were calculated on $\operatorname{poly}(\mathbf{1})$ and $\operatorname{poly}(5)$ with 21 monomer units by varying the dihedral angle $(\phi)$ of two neighboring double bonds in the backbone as the starting set of parameters. The reversal conformations were optimized by varying $\phi$ of 10 monomer units from the optimized helical structures in $10^{\circ}$ decrements. The optimized helical conformations were calculated on $\operatorname{poly}(\mathbf{6})$ with 21 monomer units by varying $\phi$ as the constraint set.

\section{RESULTS AND DISCUSSION}

\section{Polymerization in the presence of chiral PEA}

The poly(phenylacetylene)s poly(1)-poly(6) were obtained by polymerization of the corresponding achiral monomers using rhodium complex catalysts (Scheme 1). We had already succeeded in HSSP of achiral monomers $\mathbf{7}$ and $\mathbf{8}$ using a chiral catalyst system, that is, polymerization using $[\mathrm{Rh}(\mathrm{nbd}) \mathrm{Cl}]_{2}$ catalyst in the presence of $(R)-1$ phenylethylamine $((R)$-PEA) or $(S)$-1-phenylethylamine $((S)$-PEA) to yield the corresponding poly(phenylacetylene)s poly(7) ${ }^{15,16}$ and poly $(8)^{17,18}$ with enantioenriched helical conformation in solution. The preferential helical sense of $\operatorname{poly}(7)$ and $\operatorname{poly}(8)$ is kinetically stabilized by intramolecular hydrogen bonds and the bulkiness of the side groups, respectively. However, no optical activity was observed for $\operatorname{poly}(\mathbf{1})-\operatorname{poly}(\mathbf{6})$, which were prepared under the same polymerization conditions as $\operatorname{poly}(\mathbf{7})$ and $\operatorname{poly}(\mathbf{8})$, wherein $\operatorname{poly}(\mathbf{2})$ had already been reported in the study by us. ${ }^{15} \operatorname{Poly}(\mathbf{1})$-poly(5) have less steric hindrance than $\operatorname{poly}(\mathbf{8})$, which would easily lead to full racemization of polymers on the intra-chain and/or inter-chain even if the HSSP had proceeded. Monomer 6 has hydroxyl groups like monomer 7, but the optimized structure of monomer $\mathbf{6}$ showed intra-monomer hydrogen bonds, which was confirmed from the chemical shift (9.7 p.p.m.) of the hydroxyl group in ${ }^{1} \mathrm{H}$ NMR and the carbonyl stretching at $1689 \mathrm{~cm}^{-1}$ in IR. Therefore, inter-monomer hydrogen bonds would not form effectively during polymerization.

\section{Transformation to enantioenriched helical polymers in chiral solvents}

When the optically inactive poly(1)-poly(5) were dissolved in enantiopure PEA or $\beta$-pinene, induced CD signals appeared in the absorption region $(>300 \mathrm{~nm})$ of the backbone chromophore (Figure 1), while the absorption spectra maintained the initial spectra in achiral solvents, such as chloroform and THF. The Cotton effect

Table 1 Polymerization of phenylacetylene derivatives using $\mathrm{Rh}^{+}(\mathrm{nbd})\left[\left(\eta^{6}-\mathrm{C}_{6} \mathrm{H}_{5}\right) \mathrm{B}^{-}\left(\mathrm{C}_{6} \mathrm{H}_{5}\right)_{3}\right]$ in the presence of chiral PEA

\begin{tabular}{cccccc}
\hline No. & Monomers & Solvents & Yield $(\%)^{\mathrm{b}}$ & $M_{n}\left(\times 10^{4}\right)^{\mathrm{c}}$ & $M_{w} / M_{n}^{\mathrm{c}}$ \\
\hline 1 & $\mathbf{1}$ & Toluene & 80 & 3.2 & 2.2 \\
2 & $\mathbf{3}$ & $\mathrm{CHCl}_{3}$ & 80 & 3.9 & 3.1 \\
3 & $\mathbf{4}$ & $\mathrm{CHCl}_{3}$ & 62 & 7.6 & 2.2 \\
4 & $\mathbf{5}$ & $\mathrm{THF}$ & 85 & 2.8 & 3.2 \\
5 & $\mathbf{6}$ & Toluene & 59 & 1.4 & 2.8
\end{tabular}

${ }^{a}[\mathrm{M}]_{0}=0.05 \mathrm{M}(\mathrm{No} .1,3), 0.02 \mathrm{M}$ (No.2), $0.5 \mathrm{~m}$ (No.4), $0.2 \mathrm{M}$ (No.5): $[\mathrm{M}] /[\mathrm{Rh}]_{0}=25(\mathrm{No} .1,3)$ 10 (No.2), 50 (No.4), 100 (No.5); [PEA]/[Rh $]_{0}=400$ (No.1, 3, 5), 780 (No.2), 20 (No.4); $2 \mathrm{~h}$ (No. 1, 3), 33 h (No. 2), $24 \mathrm{~h}$ (No. 4), $3 \mathrm{~h}$ (No. 5); r.t; PEA: phenylethylamine. (Nothanol insoluble fraction (No.1, 3, 4, 5), hexane insoluble fraction (No.2).

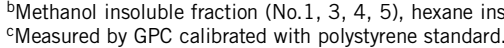




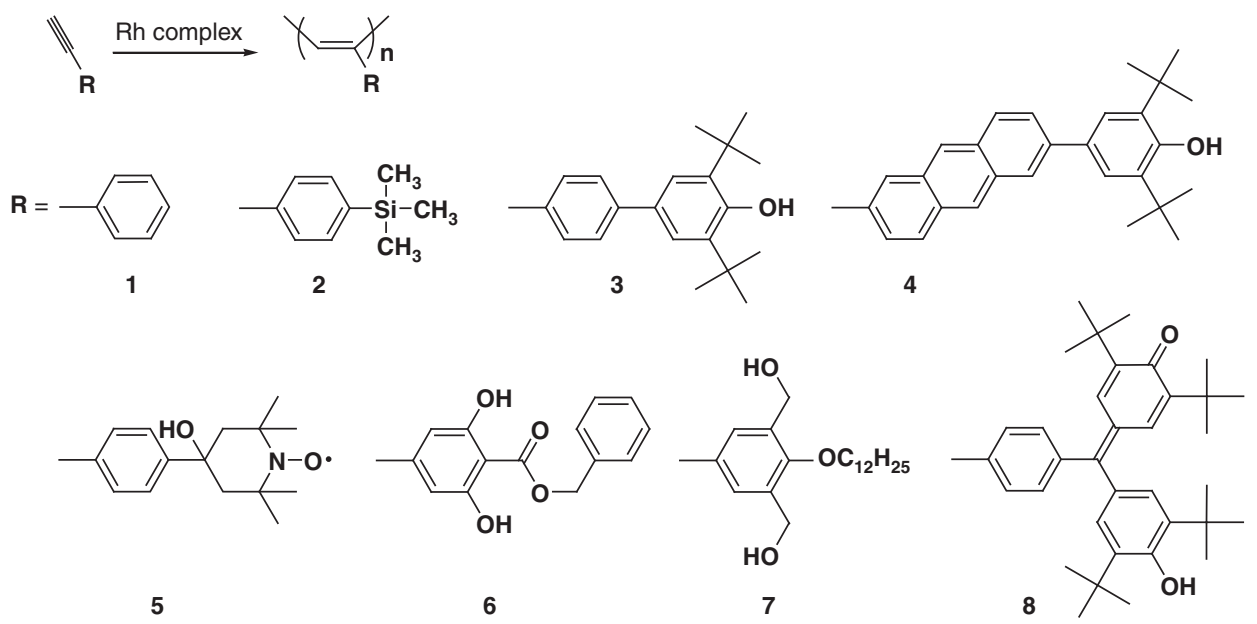

Scheme 1 Polymerization of achiral phenylacetylene analogues using rhodium complex catalysts.

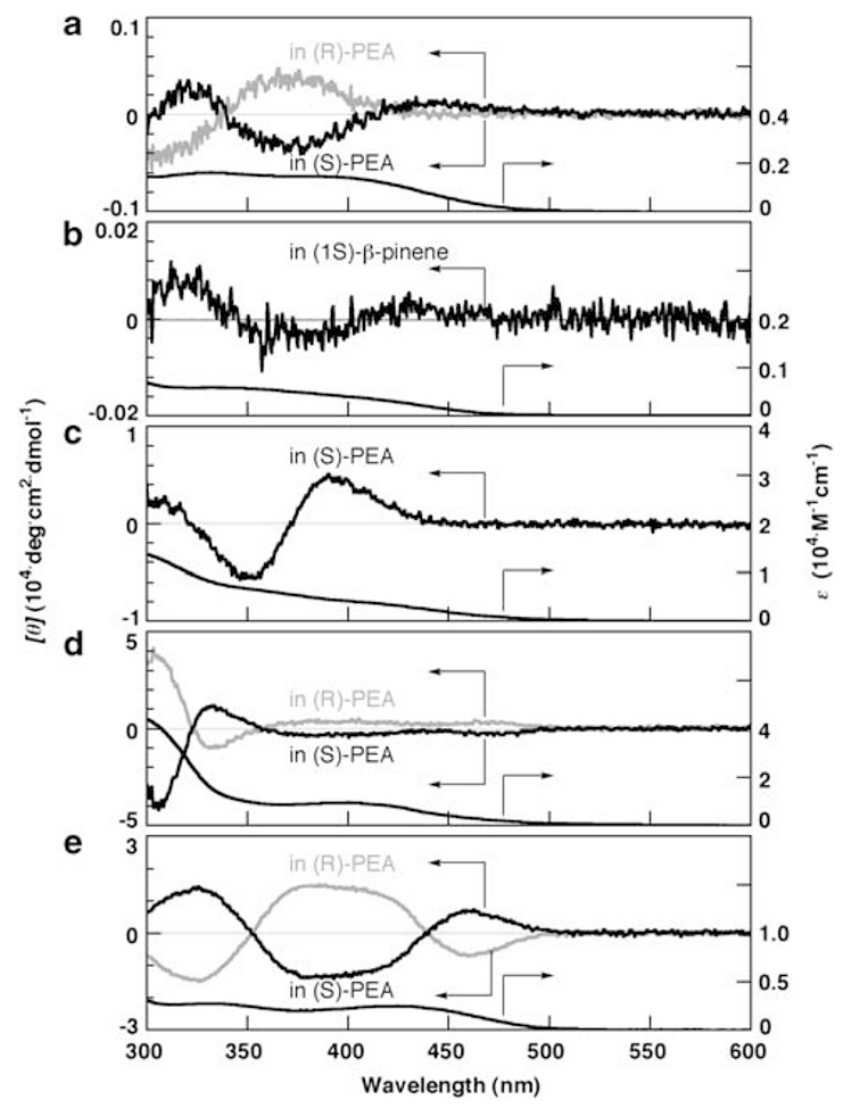

Figure 1 UV-vis and CD spectra of (a) poly(1) $(10 \mathrm{~mm})$, (b) poly(2) $(10 \mathrm{~mm})$, (c) poly(3) (1 mm), (d) poly(4) $(0.4 \mathrm{~mm})$ and (e) poly(5) $(0.8 \mathrm{~mm})$ in chiral solvents. UV, ultraviolet.

was attributed to induction of the preferential helical sense of the polyacetylene backbone because the optically active solvents did not exhibit ultraviolet-vis and CD absorption above $300 \mathrm{~nm}$. It is clear that the optically active solvents induced chiral helical bias to the energetically equivalent helical conformations of $\operatorname{poly}(\mathbf{1})-\operatorname{poly}(\mathbf{5})$. It was confirmed that this behavior did not arise from aggregation of the polymer but from the polymer in solution because a dilute solution yielded the same ultraviolet-vis and CD patterns with the same $\varepsilon$ and
$\Delta \varepsilon$ value as the original solution. Moreover, the addition of achiral solvent such as chloroform and THF to the solution in the chiral solvent decreased the CD signal intensity. This observation indicates that the energy of intermolecular interaction between the polymer and chiral solvents was comparable to that between the polymer and common achiral solvents and was smaller than that of strong interactions such as acid-base and host-guest interactions. The CD signals appeared even for the solution of the polymers without polar groups, such as $\operatorname{poly}(\mathbf{1})$ and $\operatorname{poly}(2)$.

\section{Stability of enantioenriched helical conformation}

The moderately hindered structure of the side group would be preferred for the induction of chiral helical bias because a high energetic cost of helical reversals in the polymer chain was required. In fact, poly(3)-poly(5) having hindered side groups exhibited larger anisotropy factors ( $g$-factors) and thermal stability of the CD signals compared with $\operatorname{poly}(\mathbf{1})$ and $\operatorname{poly}(\mathbf{2})$ (Figure 2). The molecular mechanics calculation supported the higher energetic cost of helical reversals for poly $(\mathbf{5})$ compared with poly(1). The optimized structures for helical and reversal conformation were calculated using MMFF94 force field on poly(1) and poly(5) with 21 monomer units as shown in Figure 3 . The energies of the reversal conformation relative to the helical conformation were calculated as $1 \mathrm{kcalmol}^{-1}$ for $\operatorname{poly}(\mathbf{1})$ and $6 \mathrm{kcalmol}^{-1}$ for $\operatorname{poly}(5)$.

Even if the chiral solvents were completely eliminated, the CD spectra retained a similar pattern to the solution CD spectra. This behavior proves that the $\mathrm{CD}$ signals of the backbone chromophore were hardly attributable to electronic interaction or orbital mixing from the chiral solvents. As an example, Figure 4 shows the CD spectra of poly(5), the thin film of which was prepared by casting the solution dissolved in (R)-PEA on a quartz plate and evaporating the solvent. When the film sample was redissolved in an achiral solvent (for example, THF), the CD signal completely disappeared, and the $(R)$ PEA-free condition was confirmed by gas chromatography (GC) analysis of the achiral solution. It was clear that the optical activity due to their helical conformations were maintained in the solid states of the polymers, even if there was no chiral molecule in the polymer.

\section{Retention of enantioenriched helical structure via hydrogen bond switching}

The visible absorption maximum of as-prepared poly $(6)$ in chloroform appears at a longer wavelength $(c a .450 \mathrm{~nm})$ due to the extended 




Figure 2 Temperature dependence of $\Delta \varepsilon / \varepsilon$ (at $380 \mathrm{~nm}$ ) of poly(1) poly(3) ( $\mathbf{\square})$ and poly(5) ( $\mathbf{\Delta})$ in enantiopure PEA.
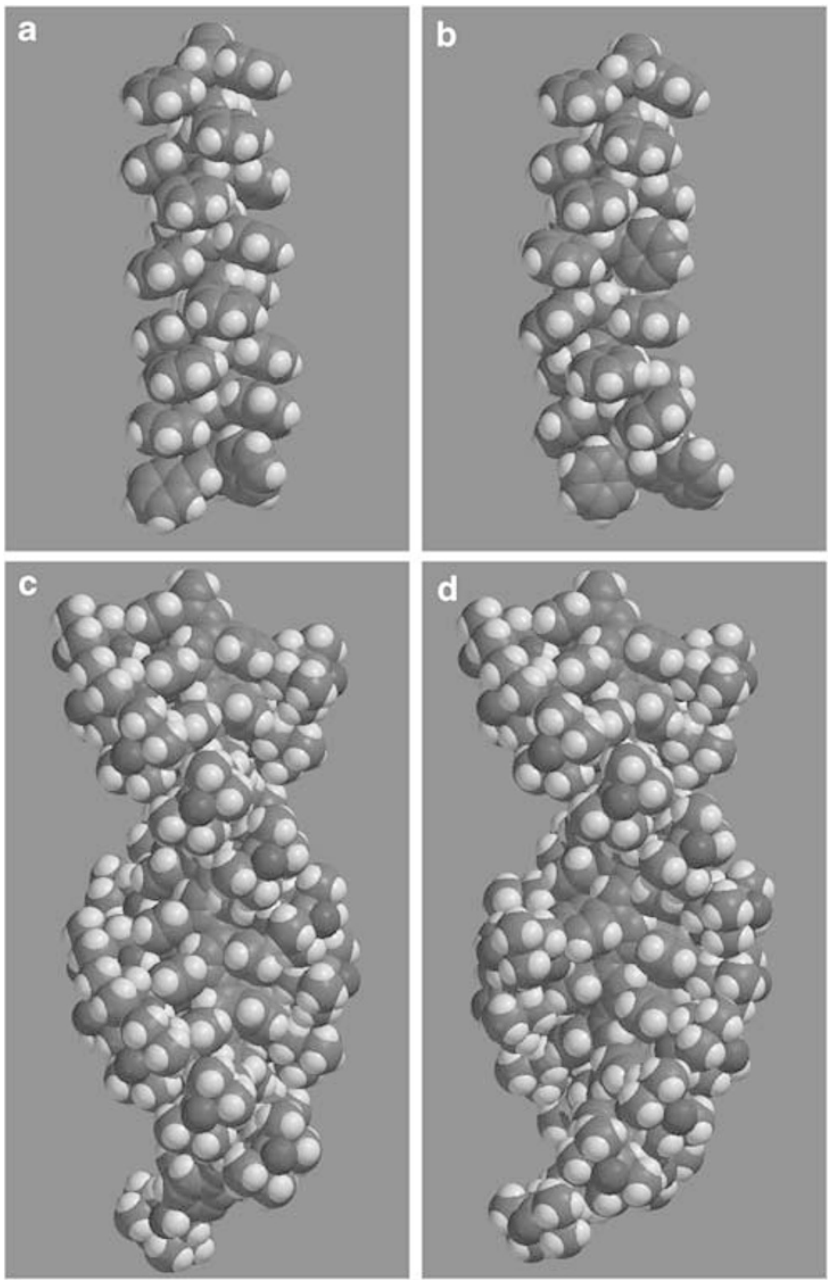

Figure 3 MMFF94-optimized structures of poly(1) and poly(5) with 21 monomer units; (a) helical and (b) reversal conformations for poly(1) and (c) helical and (d) reversal conformations for poly(5).

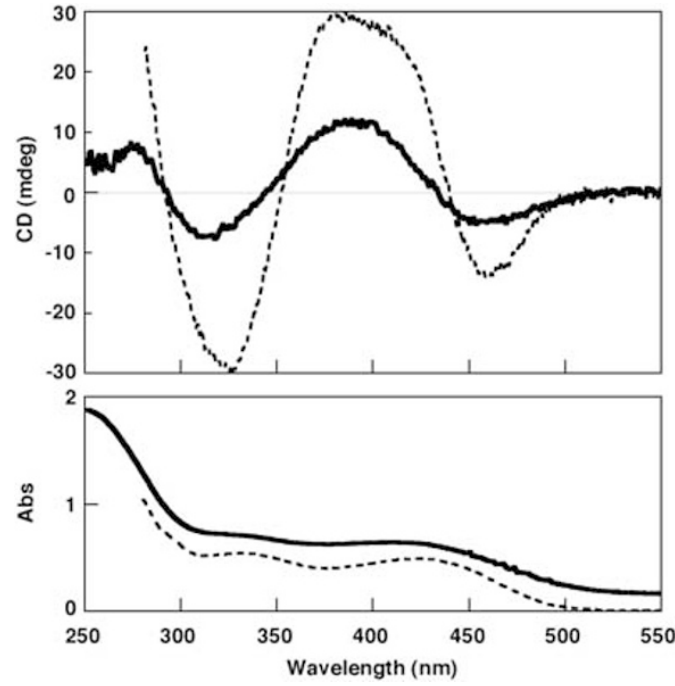

Figure 4 UV-vis and CD spectra of poly(5) in (R)-PEA (broken line) and the film (solid line) formed by the solvent-casting method from the (R)-PEA solution. UV, ultraviolet.

$\pi$-conjugation of the backbone (Figure 5a); the longer wavelength absorption was attributed to the relatively less-distorted backbone conformation with extended $\pi$-conjugation. The relatively less-distorted backbone of poly(6) and the intra-monomer hydrogen bonds would frequently induce helix inversion in the chain propagation step and vanish the preferential helical sense of the polyacetylene backbone. In enantiopure PEA, the ultraviolet-vis absorption of $\operatorname{poly}(6)$ decreased at $450 \mathrm{~nm}$ and increased at $300 \mathrm{~nm}$. These changes were accompanied by the appearance of $\mathrm{CD}$ signals (Figure $5 \mathrm{~b}$ ). It was clear that chiral PEA promoted helical transformation to induce the preferential helical sense. The solution of poly(6) dissolved in enantiopure PEA was cast on a quartz plate, and the solvent was evaporated to produce a thin film. The $\mathrm{CD}$ spectrum of the thin film exhibited a similar pattern to that of poly (6) solution in the original enantiomeric PEA (Figure 5c), and the CD pattern remained after the film sample was redissolved in an achiral solvent such as chloroform and THF (Figure 5d). Moreover, the poly (6) solution in (R)-PEA was reprecipitated into methanol, and the $\mathrm{CD}$ spectrum of the polymer thus obtained, in the achiral solvent, also exhibited a similar pattern to that of poly(6) solution in (R)-PEA (Figure 5e). The contamination and reaction of $(R)$-PEA during $(R)$-PEA solvation were ruled out because the elemental analysis of the poly(6) did not detect the presence of nitrogen. The polymer thus obtained was dissolved faster in chloroform than the preformed polymer. This fact suggests that irregular intermolecular hydrogen bonds of the preformed polymer solid were diminished through the transformation to the enantioenriched helix.

The mechanism of stabilization of the enantioenriched helical conformation is proposed to be as follows. The as-prepared poly(6) had major intra-monomer hydrogen bonds and helix reversal states that would induce intermolecular and/or irregular hydrogen bonds in solid states. When the poly (6) was dissolved in (R)-PEA, the polar $(R)$-PEA reduced the intra-monomer hydrogen bonds, and then, the carbonyl group in the side groups rotated to be perpendicular to the phenyl group. The steric hindrance of the side group increased, and the dihedral angle of two neighboring double bonds in the backbone became distorted, which promoted transformation to the enantioenriched helical conformation. When $(R)$-PEA was removed by evaporation or precipitation, the intra- and/or inter-monomer hydrogen 


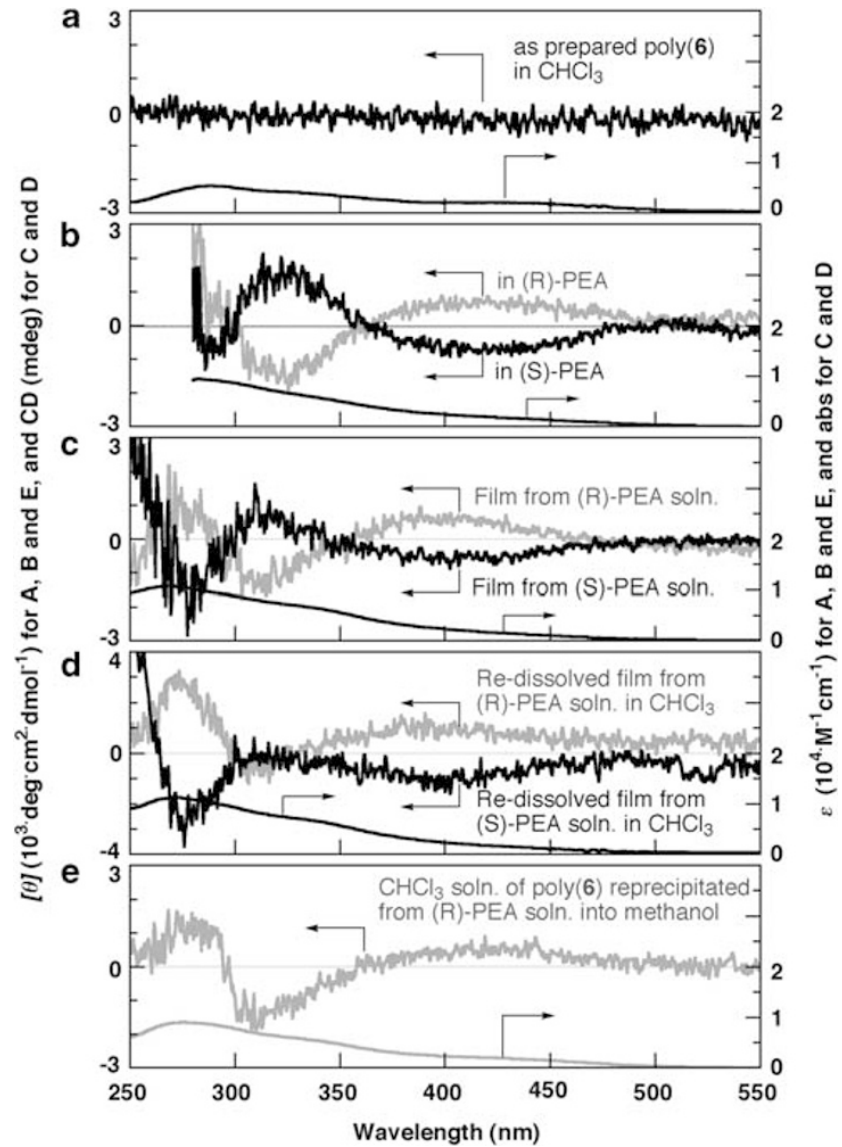

Figure 5 UV-vis and CD spectra of poly(6); (a) as-prepared poly(6) in chloroform, (b) poly(6) in (R)-and (S)-PEA, (c) poly(6) films prepared from enantiopure PEA solution, (d) chloroform solution of films prepared from enantiopure PEA solution and (e) chloroform solution of reprecipitated poly(6) after dissolution in (R)-PEA. UV, ultraviolet.

bonds in the polymer chain were reconstructed to retain the enantioenriched helical conformation, even in the achiral solvents. This speculation was supported by the molecular mechanics calculation using MMFF94 force field on $\operatorname{poly}(6)$ with 21 monomer units. The calculated energies are plotted against the dihedral angle $(\phi)$ of two neighboring double bonds in the backbone in Figure 6, and two minimum energies are observed at $\phi=150^{\circ}$ and $\phi=70^{\circ}$. The former would correspond to the as-prepared $\operatorname{poly}(6)$, and the transformation to the later, the lowest minimum energy conformer, was promoted through the hydrogen bond switching due to the solvation in $(R)$-PEA.

\section{CONCLUSIONS}

We have succeeded in producing helical poly(phenylacetylene)s possessing no chiral moieties except for helicity by transformation from the preformed racemic helical conformation to an enantioenriched helical conformation in chiral solvents, followed by removal of the chiral solvents. The transformation was successful even if the corresponding achiral monomers were unsuitable for HSSP, and the interaction between a chiral molecule and the polymer was weak like a solvent-solute interaction. Moreover, $\operatorname{poly}(6)$ in an achiral solvent such as chloroform and THF maintained its enantioenriched helical conformation; that is, the chirality of the helical sense was memorized without any other chiral or achiral additives. This finding

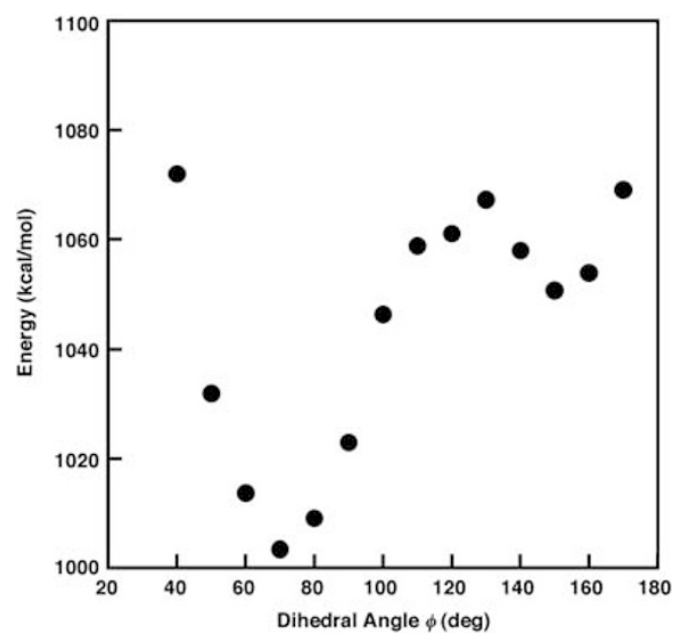

Figure 6 Relationship between the energies and the dihedral angle $(\phi)$ of two neighboring double bonds in the backbone of poly $(6)$. The energies were calculated using an MMFF94 force field on poly(6) with 21 monomer units.

is in contrast to a report by Yashima et al., ${ }^{47}$ who showed that the memory of poly((4-carboxyphenyl)acetylene)'s helicity was assisted by interaction with achiral small molecules. At this stage, the enantiopurity of the preferential helical sense is not clear, although the CD signal intensity of poly(5) in enantiopure PEA was comparable to that of poly(phenylacetylene)s bearing chiral pendant groups at the paraposition. ${ }^{19,48-50}$ However, this method is an attractive synthetic method for optically active helical polymers, as is the HSSP method, because the method does not require a chiral moiety in the monomer, thus increasing the flexibility for monomer design. For example, poly $(5)$ has a TEMPO moiety that is a stable radical often used in magnetic and redox materials.

\section{CONFLICT OF INTEREST}

The authors declare no conflict of interest.

\section{ACKNOWLEDGEMENTS}

This study was partially supported by a Grant-in-Aid for Science Research on a Priority Area 'Super-Hierarchical Structures' (Nos 19022009 and 19022010) from MEXT, and by a Grant-in-Aid for Scientific Research (B) (Nos 19350054 and 20310052) from JSPS.

1 Aoki, T., Kaneko, T. \& Teraguchi, M. Synthesis of functional $\pi$-conjugated polymers from aromatic acetylenes. Polymer 47, 4867-4892 (2006).

2 Akagi, K. Helical polyacetylene: asymmetric polymerization in a chiral liquid-crystal field. Chem. Rev. 109, 5354-5401 (2009).

3 Yashima, E., Maeda, K., lida, H., Furusho, Y. \& Nagai, K. Helical polymers: synthesis, structures, and functions. Chem. Rev. 109, 6102-6211 (2009).

4 Liu, J., Lam, J. W. Y. \& Tang, B. Z. Acetylenic polymers: syntheses, structures, and functions. Chem. Rev. 109, 5799-5867 (2009).

5 Nolte, R. J. M., van Beijnen, A. J. M., \& Drenth, W. Chirality in polyisocyanides. J. Am. Chem. Soc. 96, 5932-5933 (1974).

6 Okamoto, Y., Suzuki, K., Ohta, K., Hatada, K. \& Yuki, H. Optically active poly(triphenylmethyl methacrylate) with one-handed helical conformation. J. Am. Chem. Soc. 101, 4763-4765 (1979).

7 Kamer, P. C. J., Nolte, R. J. M. \& Drenth, W. Screw sense selective polymerization of achiral isocyanides catalyzed by optically active nickel(II) complexes. J. Am. Chem. Soc. 110, 6818-6825 (1988).

8 Deming, T. J. \& Novak, B. M. Enantioselective polymerizations of achiral isocyanides. Preparation of optically active helical polymers using chiral nickel catalysts. J. Am. Chem. Soc. 114, 7926-7927 (1992). 
9 Ito, Y., Ohara, T., Shima, R. \& Suginome, M. Highly screw-sense selective polymerization of 1,2-diisocyano-3,6-di-p-tolylbenzene initiated by optically active binaphthylpalladium(II) complexes. J. Am. Chem. Soc. 118, 9188-9189 (1996).

10 Habaue, S., Seko, T. \& Okamoto, Y. Copper(I)-catalyzed asymmetric oxidative coupling polymerization of 2,3-dihydroxynaphthalene using bisoxazoline ligands. Macromolecules 36, 2604-2608 (2003).

11 Tian, G., Lu, Y. \& Novak, B. M. Helix-sense selective polymerization of carbodiimides: building permanently optically active polymers from achiral monomers. J. Am. Chem. Soc. 126, 4082-4083 (2004).

12 Akagi, K., Piao, G., Kaneko, S., Sakamaki, K., Shirakawa, H. \& Kyotani, M Helical polyacetylene synthesized with a chiral nematic reaction field. Science 282, 1683-1686 (1998).

13 Goto, H. \& Akagi, K. Optically active conjugated polymers prepared from achiral monomers by polycondensation in a chiral nematic solvent. Angew. Chem. Int. Ed. Engl. 44, 4322-4328 (2005).

14 Holder, S. J., Achilleos, M. \& Jones, R. G. Increasing molecular weight parameters of a helical polymer through polymerization in a chiral solvent. J. Am. Chem. Soc. 128 12418-12419 (2006).

15 Aoki, T., Kaneko, T., Maruyama, N., Sumi, A., Takahashi, M., Sato, T. \& Teraguchi, M. Helix-sense-selective polymerization of phenylacetylene having two hydroxy groups using a chiral catalytic system. J. Am. Chem. Soc. 125, 6346-6347 (2003).

16 Sato, T., Aoki, T., Teraguchi, M., Kaneko, T. \& Kim, S.- Y. Role of chiral amine cocatalysts in the helix-sense-selective polymerization of a phenylacetylene using a catalytic system. Polymer 45, 8109-8114 (2004).

17 Umeda, Y., Kaneko, T., Teraguchi, M. \& Aoki, T. Helix-sense-selective polymerization of a phenylacetylene bearing an achiral and bulky galvinoxyl moiety. Chem. Lett. 34, 854-855 (2005).

18 Kaneko, T., Umeda, Y., Yamamoto, T., Teraguchi, M. \& Aoki, T. Assignment of helical sense for poly(phenylacetylene) bearing achiral galvinoxyl chromophore synthesized by helix-sense-selective polymerization. Macromolecules 38, 9420-9426 (2005).

19 Teraguchi, M., Mottate, K., Kim, S.- Y., Aoki, T., Kaneko, T., Hadano, S. \& Masuda, T. Synthesis of chiral helical poly(hydroxyl-containing phenylacetylene) membranes by insitu depinanylsilylation and their enantioselective permeabilities. Macromolecules $\mathbf{3 8}$ 6367-6373 (2005)

20 Yashima, E., Matsushima, T. \& Okamoto, Y. Poly((4-carboxyphenyl)acetylene) as a probe for chirality assignment of amines by circular dichroism. J. Am. Chem. Soc. 117, 11596-11597 (1995)

21 Majidi, M. R., Kane-Maguire, L. A. P., \& Wallace, G. G. Chemical generation of optically active polyaniline via the doping of emeraldine base with (+)- or (-)camphorsulfonic acid. Polymer 36, 3597-3599 (1995).

22 Schlitzer, D. S. \& Novak, B. M. Trapped kinetic states, chiral amplification and molecular chaperoning in synthetic polymers: chiral induction in polyguanidines through ion pair interactions. J. Am. Chem. Soc. 120, 2196-2197 (1998).

23 Maeda, K., Yamamoto, N. \& Okamoto, Y. Helicity induction of poly(3-carboxypheny isocyanate) by chiral acid-base interaction. Macromolecules 31, 5924-5926 (1998).

24 Yashima, E., Maeda, K. \& Yamanaka, T. Helicity induction and conformational dynamics of poly(bis(4-carboxyphenoxy)phosphazene) with optically active amines. J. Am. Chem. Soc. 122, 7813-7814 (2000).

25 Ishikawa, M., Maeda, K. \& Yashima, E. Macromolecular chirality induction on optically inactive poly(4-carboxyphenyl isocyanide) with chiral amines: a dynamic conformational transition of poly(phenyl isocyanide) derivatives. J. Am. Chem. Soc. 124, 7448-7458 (2002).

26 Prince, R. B., Barnes, S. A. \& Moore, J. S. Foldamer-based molecular recognition. J. Am. Chem. Soc. 122, 2758-2762 (2000).

27 Tanatani, A., Mio, M. J. \& Moore, J. S. Chain length-dependent affinity of helical foldamers for a rodlike guest. J. Am. Chem. Soc. 123, 1792-1793 (2001).

28 Nonokawa, R. \& Yashima, E. Helicity induction on a poly(phenylacetylene) derivative bearing aza-18-crown-6 ether pendants in water. J. Polym. Sci. Polym. Chem. Ed. 41, 1004-1013 (2003).

29 Sakai, R., Satoh, T., Kakuchi, R., Kaga, H. \& Kakuchi, T. Macromolecular helicity induction for novel optically inactive poly(phenyl isocyanate) bearing crown ether based on the host-guest complexation. Macromolecules 36, 3709-3713 (2003).
30 Abe, H., Masuda, N., Waki, M. \& Inouye, M. Regulation of saccharide binding with basic poly(ethynylpyridine)s by $\mathrm{H}^{+}$-induced helix formation. J. Am. Chem. Soc. 127, 16189-16196 (2005).

31 Li, C., Numata, M., Bae, A.- H., Sakurai, K. \& Shinkai, S. Self-assembly of supramolecular chiral insulated molecular wire. J. Am. Chem. Soc. 127, 4548-4549 (2005).

32 Green, M. M., Khatri, C. \& Peterson, N. C. A macromolecular conformational change driven by a minute chiral solvation energy. J. Am. Chem. Soc. 115, 4941-4942 (1993).

33 Khatri, C. A., Pavlova, Y., Green, M. M. \& Morawetz, H. Chiral solvation as a means to quantitatively characterize preferential solvation of a helical polymer in mixed solvents. J. Am. Chem. Soc. 119, 6991-6995 (1997).

34 Dellaportas, P., Jones, R. G. \& Holder, S. J. Induction of preferential helical screw senses in optically inactive polysilanes via chiral solvation. Macromol. Rapid Commun. 23, 99-103 (2002)

35 Nakashima, H., Koe, J. R., Torimitsu, K. \& Fujiki, M. Transfer and amplification of chiral molecular information to polysilylene aggregates. J. Am. Chem. Soc. 123, 4847-4848 (2001).

36 Kawauchi, T., Kumaki, J., Kitaura, A., Okoshi, K., Kusanagi, H., Kobayashi, K., Sugai, T., Shinohara, H. \& Yashima, E. Encapsulation of fullerenes in a helical PMMA cavity leading to a robust processable complex with a macromolecular helicity memory. Angew. Chem. Int. Ed. Engl. 47, 515-519 (2008).

37 Kawagoe, Y., Fujiki, M. \& Nakano, Y. Limonene magic:noncovalent molecular chirality transfer leading to ambidextrous circularly polarised luminescent $\pi$-conjugated polymers. New J. Chem. 34, 637-647 (2010)

38 Rizzo, P., Daniel, C. \& Guerra, G. Chiro-optical materials based on a racemic polymer. Macromolecules 43, 1882-1887 (2010)

39 Aoki, T., Nakahara, H., Hayakawa, Y., Kokai, M. \& Oikawa, E. Trimethylsilyl-group containing polyphenylacetylenes for oxygen and ethanol permselective membranes. J. Polym. Sci. Polym. Chem. Ed. 32, 849-858 (1994).

40 Malakhov, A. D., Skorobogatyi, M. V., Prokhorenko, I. A., Gontarev, S. V., Kozhich, D. T., Stetsenko, D. A., Stepanova, I. A., Shenkarev, Z. O., Berlin, Y. A. \& Korshun, V. A. 1(Phenylethynyl)pyrene and 9,10-bis(phenylethynyl)anthracene, useful fluorescent dyes for DNA labeling: excimer formation and energy transfer. Eur. J. Org. Chem. 2004, 1298-1307 (2004).

41 Inoue, K., Koga, N. \& Iwamura, H. An approach to organic ferromagnets. Synthesis and characterization of 1-phenyl-1,3-butadiyne polymers having a persistent nitroxide group on the phenyl ring. J. Am. Chem. Soc. 113, 9803-9810 (1991).

42 Nishide, H., Kaneko, T., Yoshioka, N., Akiyama, H., Igarashi, M. \& Tsuchida, E. Poly[[4( $\mathrm{N}$-tert-butyl-N-hydroxyamino)phenyl]acetylene] and the magnetic property of its radical derivative. Macromolecules 26, 4567-4571 (1993).

43 Elix, J. A., Jiang, H. \& Wardlaw, J. H. A new synthesis of xanthones. 2,4,7-Trichloronorlichexanthone and 4,5,7-trichloronorlichexanthone, two new lichen xanthones. Aust. J. Chem. 43, 1745-1758 (1990).

44 Seidemann, R. \& Dulog, L. N-Carboxyanhydride of 4-amino-4-carboxy-2,2,6,6tetramethylpiperidine-1-oxyl, a new paramagnetic monomer. Makromol. Chem. 187, 2545-2551 (1986).

45 Neuville, L., Bigot, A., Tran Huu Dau, M. E. \& Zhu, J. 4-Nitrophenyltriflate and 4nitrophenylnonaflate as new perfluoroalkanesulfonyl transfer agents: experimental and computational studies. J. Org. Chem. 64, 7638-7642 (1999).

46 Henry, K. M. \& Townsend, C. A. Synthesis and fate of 0 -carboxybenzophenones in the biosynthesis of aflatoxin. J. Am. Chem. Soc. 127, 3300-3309 (2005).

47 Yashima, E., Maeda, K. \& Okamoto, Y. Memory of macromolecular helicity assisted by interaction with achiral small molecules. Nature 399, 449-451 (1999).

48 Aoki, T., Kokai, M., Shinohara, K. \& Oikawa, E. Chiral helical conformation of polyphenylacetylene having optically-active bulky substituents. Chem. Lett. 22, 2009-2012 (1993)

49 Shinohara, K., Aoki, T. \& Kaneko, T. Helical chirality of $\pi$-conjugated main-chain induced by polymerization of phenylacetylene with chiral bulky pinanyl groups: effects of the flexible spacer and polymerization catalyst. J. Polym. Sci. Polym. Chem. Ed. 40, 1689-1697 (2002).

50 Aoki, T., Fukuda, T., Shinohara, K., Kaneko, T., Teraguchi, M. \& Yagi, M. Synthesis of chiral helical poly[ $p$-(oligopinanylsiloxanyl)phenylacetylene]s and enantioselective permeability of their membranes. J. Polym. Sci. Polym. Chem. Ed. 42, 4502-4517 (2004). 